This item was submitted to Loughborough's Research Repository by the author.

Items in Figshare are protected by copyright, with all rights reserved, unless otherwise indicated.

\title{
The experiences of cancer patients within the material hospital environment: three ways that materiality is affective
}

\section{PLEASE CITE THE PUBLISHED VERSION}

https://doi.org/10.1016/j.socscimed.2020.113402

\section{PUBLISHER}

Elsevier BV

VERSION

AM (Accepted Manuscript)

\section{PUBLISHER STATEMENT}

This paper was accepted for publication in the journal Social Science \& Medicine and the definitive published version is available at https://doi.org/10.1016/j.socscimed.2020.113402.

\section{LICENCE}

CC BY-NC-ND 4.0

\section{REPOSITORY RECORD}

Wiltshire, Gareth, Emma Pullen, Frankie F Brown, Mike Osborn, Sarah Wexler, Mark Beresford, Mark Tooley, and James E Turner. 2020. "The Experiences of Cancer Patients Within the Material Hospital Environment: Three Ways That Materiality Is Affective”. Loughborough University. https://hdl.handle.net/2134/13066595.v1. 


\title{
Title
}

The experiences of cancer patients within the material hospital environment: three ways that materiality is affective

\begin{abstract}
Improving the patient experience is widely recognised as an important goal in the delivery of high-quality healthcare. This study contributes to this goal with a particular focus on the role of the material hospital environment for patients being treated for cancer. Extending the burgeoning literature utilising materialist theoretical approaches in social science and medicine, we report on qualitative data with 18 participants who had received cancer treatment from one UK hospital. Our analysis offers a typology of ways in which the material hospital environment is affective: through patients' direct intra-actions with nonhuman materiality; through providing shared spaces within which human-human assemblages are actualised; and through being the material component of the practices of treatment. Within each process in this typology, the analysis highlights how the affective feeling states which play a critical role in patient wellbeing are in many ways contingent, fluid and context-sensitive. Amidst ambitions to improve the patient experience, these findings underline the significance of materialities of care and offer a broad explanatory typology with analytic and practical potential for healthcare staff, patient groups, architects and designers.
\end{abstract}

\section{Keywords}

Cancer; Sociology; Materialism; Hospitals; Architecture; Patient experience; Medicine. 


\section{Introduction}

Cancer continues to be a substantial burden of disease with an estimated 17 million new diagnoses worldwide annually (GCO, 2019) and around 360,000 cases in the UK alone (Cancer Research UK, 2019). Depending on cancer type and staging, patients are treated with a range of therapeutic interventions in hospital settings such as surgery, chemotherapy, radiotherapy, hormonal and small molecule therapies, and more recently, immuno-therapies. Given that there are consistent positive associations between patient experience, patient safety and clinical effectiveness across a range of illnesses and treatments (Doyle et al., 2013; Devlin and Arneill, 2003) it is not surprising that patient experience is widely recognised as a vital element of highquality healthcare at a policy level (DH, 2008a) and that a number of studies have been directed at understanding cancer patients' experiences of treatment (see Cunningham and Wells, 2017; Foglino et al., 2016; Bettencourt et al., 2007).

The material hospital environment has been highlighted as a matter of concern within patient experience research (Schreuder et al. 2016) and quality healthcare has long been central to architectural and design ambitions (Martin et al. 2015; Nettleton et al., 2018). Indeed, Andrews et al. (2014, p. 211) assert that there is "a growing realisation across health and social sciences that "place matters' to health and healthcare." Despite early investigations which suggested that enhancing hospital environments - such as views through a window - can reduce patient recovery times (Ulrich, 1991; 1984), the evidence of the positive impact of hospital environments on clinical outcomes has been modest, mixed and somewhat contingent (Selami et al., 2017; Williams, 1998). Nevertheless, without relinquishing the prospect of understanding the implications of hospital environments for clinical outcomes (direct or indirect), there is a large body of work examining the complex psychological, sociological and geographical relationships between hospital environments and quality healthcare which is 
grounded in expanded notions of health and wellbeing beyond biomedical definitions of being 'disease-free'.

Against this backdrop, the importance of the hospital environment has been researched in a variety of ways. For example, Arneill and Devlin (2002) demonstrate that perceived quality of care is higher in spaces deemed more palatable to patients (well furnished, light and containing artwork) and Schreuder et al. (2016) illustrate that patients' self-reported wellbeing is most likely to be influenced by spatial comfort, safety and security, and autonomy. Indeed, hospital spaces have been shown to have a negative impact on the quality of care provided (Melo, 2018) as well as reducing the ability of nurses to optimally care for multiple patients when private rooms are used (Donetto et al., 2017). In an extensive review by Huisman et al. (2012), it was found that the physical environment can have an effect on the healing process as well as the wellbeing of patients in large part through helping to reduce errors, falls and infections, and improving privacy, comfort and control.

Underpinned by approaches derived from medical sociology and health geography, Gesler et al. (2004) challenge the medical discourses which allow clinical care to take priority in hospital design and argue for "the need to consider the symbolic and social importance of the buildings in which health care is delivered, as well as the physical aspects of the built form of hospital buildings". Furthermore, such medical discourses were also considered by Bell (2018) who highlighted the place-specific tensions and power dynamics that arise within the highly institutionalised biomedical space of the hospital. Most recently, Wright's (2019) study found that the hospital foyer exacerbated patients' pre-existing anxieties, the main waiting room both soothed and aggravated attendees' concerns and the atrium was experienced as an affective atmosphere which provided "a space to breathe" - issues which clearly impact the patient experience. 
It is our intention to contribute to this growing body of work which takes seriously the notion that the material environment of hospital settings plays a significant role in the experience of care. Our objective is to address the relative gap in the literature investigating the role of the material hospital environment in relation to the particularities of cancer treatment with a view to inform the work of multiple stakeholders involved in improving quality of care for future patients. In what follows, we explain our underpinning theoretical approach before describing our methods and presenting our findings. The paper concludes with a return to the objectives of the research by offering some suggestions for policy and practice.

\section{Materialist approaches in social science and medicine}

We ground this paper theoretically within the rich and burgeoning trend in social science towards incorporating material, nonhuman objects in the investigation of human experience. Scholarship advocating for materialist approaches has drawn from a range of established theoretical frameworks, including actor-network theory (see Latour, 2005; 1996), assemblage theory (see Deleuze and Guattari, 1987), agential realism (see Barad, 2007; 2003) and non-representational theory (see Thrift, 2008; Lorimer, 2005) as well as more recent articulations such as new materialism (see Coole and Frost, 2010), feminist new materialism (see Lupton, 2019; Fullagar, 2017) and the material elements within contemporary social practice theories (see Shove et al., 2012). Although there are nuanced divergences between different materialist traditions which should not be ignored, a shared affinity has been the dissatisfaction with the anthropocentric tendencies of philosophy and social theory in the second half of the twentieth century which was disproportionately concerned with social constructivist, discursive and hermeneutic positions. That is, "a sizeable portion of the world what happens 'out there' in everyday life has been suffocated and remains unrepresented by social constructivist research" (Andrews at el., 2014, p. 211). Beyond this starting point, we 
align with Fox and Alldred (2016, p.289) in recognising that two core principles undergird current ambitions of materialist approaches; "the first concerning a shift from essentialism to relationality and the second acknowledging the capacity of nonhuman things, organizations and even abstract concepts to affect".

Concerning the first of these principles, materialist approaches assume that the given properties of patients and buildings are not the focus of research, but rather it is "what people and things become as a result of their position in a network" and how these properties "form dynamic configurations of human and nonhuman actors" (Greenhalgh and Stones, 2010, p. 1287). In this way, patients, buildings, doctors and medicine - for example - are not discrete entities; they make up "entangled" (Timmons et al., 2019) component parts of "relational encounters" (Andrews and Duff, 2019). For many, these dynamic configurations - or 'assemblages' - of human and nonhuman elements have become the unit of analysis in health and healthcare research leading to a greater awareness of the properties of materials and their temporal and spatial organisation.

What this means for patient experience research is that 'experience' is not merely about participants' meanings or conscious descriptions (although these are not to be ignored), but also about the emergence of affective 'feeling states' which occur prior to cognitive understanding. As Andrews et al. (2014) explain;

affect is a mobile energy; an intensity which is the result of the relative movements and interactions between things from atoms and molecules to fully formed human bodies and nonhuman objects in space. Whilst initially affect is a purely physical non-cognitive event, it gives rise to less-than-fully conscious experiences. These are felt sensations or 'feeling states' that, preceding full cognition (thoughts and emotions for example), manifest on a somatic register as vague but intense 'atmospheres' or 'vibes'.

The second principle that we consider important to draw on is the clear shift towards appreciating the properties of nonhuman objects as things in themselves with causal potentials. 
This point represents the attempt to develop a properly post-anthropocentric theoretical perspective that pays attention to the 'intra-action' of human and nonhuman objects, or following Andrews et al. (2014), "the human body's co-evolution with co-equal nonhumans". In the language of actor-network theory, a nonhuman object that can "modify a state of affairs by making a difference" is referred to as a 'actor' (or 'actant' if it has no configuration) (Latour, 2005, p.71). In this way, nonhuman objects are "not simply the hapless bearers of symbolic projection" (Latour, 2005, p.10) which implies "no special motivation of human individual actors, nor of humans in general" (Latour, 1996, p.375). In a similar way, within contemporary social practice theories - and, in particular, Shove et al.'s (2012) three-elements model - Maller (2015) explains that conscious humans are 'decentred' from the analysis which helps reframe and rebalance empirical investigations. In her view, this approach "reveals the agency of things in daily routines which, aside from cultural studies research, are often rendered invisible, collapsed into human agency or relegated to the background as context”. From this perspective, materiality is essential because a practice is only realised with the presence of necessary material things and their integration with meanings and competences in the moment of acting.

Advancements made by this body of work have attempted to shed light on a range of topics relevant to social science and medicine. Andrews et al. (2014) use their qualitative research to illuminate the promise of materialist perspectives for investigating wellbeing, arguing that by avoiding the error of privileging human subjects, wellbeing can better be understood as something not "taken from environment", but instead as something that might "emerge as the affective environment". Similarly, Ivanova et al. (2016) note how the assemblage of social and material objects intra-act to form what they call 'carescapes', thus providing a more effective conceptualization of 'place' which is not rigid or fixed, but ephemeral, contingent and ambiguous. Turning attention to how materiality shapes the enactment of medicine, several papers have examined practices of care including investigations 
into interprofessional care for cardiac patients (McDougall et al., 2016), the integration of new technologies in the operating theatre (Linderg et al., 2017), and the way in which mundane materialities constitute, mediate and enable healthcare (Brownlie and Spandler, 2018). Indeed, in their analysis of the intertwined practices involved in the various 'pathways' or 'journeys' that brain tumour patients are navigated through, Llewellyn et al. (2018) position nonhuman materialities as actants capable of shaping the movements of others. On the issue of power, Gardner and Cribb (2016) offer up a new understanding of the role of nonhuman elements in structuring power relations between clinicians, patients and families, as clinicians engage in patient-centred ethical work. This capability highlights the theoretical shift within materialist approaches that attribute causal powers to nonhuman objects and undermines the idea that human actors are the sole possessors of causal power in the domain of patient experience.

Several recent papers have particular relevance to this present study exploring cancer patients' experiences within the material hospital environment. Martin et al.'s (2015) paper attempts to develop a place-sensitive sociology of healthcare architecture and, in doing so, draws influence from medical geography and places hospital architectural trends within a detailed historical context. Commenting on the contemporary norms whereby hospital buildings mirror aspects of design from retail sectors, they conclude that,

it is not simply the case that the architecture of health care reflects wider moves towards neoliberal forms of subjectivity, whereby patients are construed as consumers and responsibilised citizens; rather, it is our argument that architecture plays a more active role in shaping and configuring such changes (p. 1018)

Making conceptual advancements to material culture within health contexts, Buse et al. (2018) introduce the term 'materialities of care' and describe three strands; spatialities of care, temporalities of care and practices of care. For Buse et al. (2018), materialities should not be studied as a backdrop within which healthcare takes place, but active objects in constituting relations of care that shape, enable or constrain practices of caring. In the context of one 
particular provider of cancer-specific centres (Maggie's Centres), Martin et al. (2019, p.1) pay attention to the light, material and shape within the buildings to highlight how they become "emotionally charged buildings that shape the ways in which care is staged, practiced and experienced in everyday ways through the orchestration of architectural atmospheres". Indeed, the same centres were described by Butterfield and Martin (2016) as "affective sanctuaries" within which patients are afforded private places for emotional retreat.

In our study of the relationship between the material environment of the hospital and the experience of patients going through cancer treatment, we draw much inspiration from this body of work. Specifically, we pay attention to the ways in which affect emerges from the relational configurations between the patients and the objects encountered as part of cancer treatment (including medical equipment, chairs and wards) as well as objects encountered as part of the general hospital architecture and design (including corridors, artwork and waiting rooms). Indeed, we also seek to explore how materials can shape social interactions (such as patient-patient, patient-staff and patient-visitor interactions) as well as how materials have properties which impact the practices of care. In exploring these research aims, we build on questions raised in previous studies concerning the feel of care at a sensory level and the way that materials are imagined by patients (Buse et al., 2018).

\section{Methodology}

This research forms part of a wider ongoing interdisciplinary project investigating the impact of cancer treatment on a range of physiological and lifestyle outcomes ${ }^{1}$. Following ethical approval at both NHS and institutional level (IRAS ID: 214849; REC Ref:

\footnotetext{
${ }^{1}$ The ongoing project is a collaboration between a team of university-based researchers and clinical practitioners at one medium-sized acute hospital trust in the UK. This paper presents the initial dataset of a wider comparative study exploring the impact of hospital design on cancer patients' experiences as they receive treatment within the existing and new clinical facilities.
} 
17/SW/0020), the patient experience phase of the project was conducted with a total of 18 patients who were recruited to take part through invitations during clinical visits and support group meetings. The participant sample was diverse in terms of diagnosis (including patients treated for breast cancer, Hodgkin lymphoma, non-Hodgkin lymphoma, and prostate cancer), age (ranging from 32-80), gender (7 male and 11 female) and treatment received (see Table 1 in the supplementary materials for participant characteristics details). All participants provided written consent before taking part.

Participants took part in one of the four focus group interviews organised by diagnosis type lasting between 100 minutes and 150 minutes. During the focus group interviews, participants' perceptions of the hospital environment were firstly captured using two standardised questionnaires ${ }^{2}$. While the responses to the questionnaires are not reported here, participants' discussions around the completion of questionnaires served to elicit meaningful data in places and was included for later qualitative analysis. The focus group moderator facilitated discussion around two starter questions: "Which features of the hospital building are good/not so good for wellbeing?" and "What kinds of visual and sensory features bring on feelings of pleasure or discomfort in the building?" Numerous additional questions and probes were asked as part of the dynamic conversation typical in focus groups.

Focus group audio files were transcribed verbatim resulting in a 42,000-word document for analysis. This analysis resulted in the emergence of three ways in which the material environment of the hospital was related to the experience of cancer patients (see Table 2 in the supplementary material for a summary of findings). We arrived at these findings through a rigorous process broadly driven by realist approaches to qualitative research (see Ronkainen and Wiltshire, 2019; Maxwell, 2012; Sayer, 2000) in which threats to validity are guarded

\footnotetext{
${ }^{2}$ The questionnaires used with participants were (1) The Perceived Hospital Environment Quality Indicators (Andrade et al., 2012) and (2) A Staff and Patient Environment Calibration Tool (DH, 2008b). Analysis of this data will be published elsewhere once the comparative phase of the research project has been completed.
} 
against through the use of several key principles and procedures. Firstly, two experienced qualitative researchers (first and second authors) independently engaged in a close reading of the transcripts while annotating initial codes before combining their analyses in a consensus meeting. Initial codes developed into more robust categories against standards of empirical adequacy as well as existing theoretical and empirical understandings. The emerging claims were then put to two co-authors (who were not involved in data analysis) who helped to critique and refine the interpretation and, finally, were also shared directly with participants in an email asking for feedback ${ }^{3}$. The underpinning intention throughout the process was to expose research claims to disputations and alternative accounts in the interest of increasing our confidence in our interpretation.

\section{Findings}

\subsection{Affective qualities between patients and the nonhuman environment}

The first way in which the material environment of the hospital related to cancer patients' experiences in our study was through the proximal, direct and sensory intra-actions between patients and nonhuman materials. For example, numerous patients reported noticing affective feeling states of being relaxed, calm and restful during momentary points of connection with 'natural' elements within the environment - a phenomenon acknowledged across the green space and blue space literature in health geography (Coleman and Kearns, 2015; Foley, 2015; Maas et al., 2006; De Vries et al., 2003). One participant enjoyed the sight of the floral arrangement at the reception desk as she entered the hospital foyer, and a fish tank that was previously kept by reception was well-received "because it's very relaxing." Both of

\footnotetext{
${ }^{3}$ Participants were emailed a copy of Table 2 (summary of findings in supplementary material) and a short survey where they were asked to what extent they agree with each of the research claims (i.e. each row on the summary of findings).
} 
these ephemeral feeling states rely on the visual field of the patients as they unconsciously recognise and begin to co-produce the 'pre-emotional' affective qualities that direct lived experience. Interestingly, the pleasant intra-actions with nature were also experienced when those elements were artificial depictions. Indeed, one patient claimed, "I quite like visual scenes of environment - mountains and streams that sort of thing. That is pretty commonplace [in this hospital] and it's quite restful.” As another participant explained:

There's this artificial window that's got blue sky and a tree with blossom on, and suddenly it was just really lovely to see that, although it's completely artificial. And also the little room you have to wait in for an hour while things are draining through you, they've got beautiful paintings on the wall and wildlife and lavender and things. And I remember that and just thinking 'wow this is almost like being outside again.'

Connections can be drawn here with Nettleton's (2015) use of Dewey's 'art as experience' which expresses the ways in which both natural landscapes and art produce moments of aesthetic appreciation. Indeed, Martin et al.'s (2019) article within cancer centres in the UK brings artwork into the conversation about how particular 'atmospheres' are produced through the introduction of colour and light. Such examples speak to the theoretical perspective offered within materialist approaches in revealing how the patient is not the central generative subject in the production of emotion, but neither are they the passive object at the end of a linear causal chain of events.

Further explaining the importance of the visual field in this assemblage, the absence of more pleasant visual offerings was noticeable in the data. For example, one participant noticed the absence of nature describing how the windows were too high to benefit from a direct line of sight to the ground-level outside area, claiming "you can't even see a tree moving or anything." This led to patients yearning for more pleasant sights, as explained by another participant who said, "you just think 'if only that were a nice garden space that you could wheel your drip out to and get a glimpse of cloud'." Importantly, the absence of the visual scenes 
sought by patients - and the absence of ephemeral feeling states that they are associated with - bring into focus an everyday example of wellbeing failing to emerge within the hospital setting. Pleasant feeling states were also experienced when intra-acting with artwork such as an exhibition of photographs within the oncology department building. Looking at the photographs in the exhibition was described as a "delight" in a rather immediate sense, but it was also noted that "there are ones that you just see and you forget what you're here for." Here, the momentary 'forgetting' was meaningful for the patient, reminding us that pleasant affective states may manifest within the temporary context of patients' present circumstances, not just because of the exhibition itself. Indeed, while it is important to appreciate that different patients at different times will have different experiences of the visual scenes, the participants in our study reported remarkably similar experiences, suggesting that more enduring regularities can also be expected.

Pleasant patient experiences, however, were often countered by the less pleasant experiences of both poor lighting and the structural form of what they considered to be an "old" building. In particular, several participants described the "low ceilings" in the hospital and that it was "dark" which was interpreted as feeling "depressing." Indeed, a breast cancer patient attributed a rather intense feeling state to the sight of the door which provided entrance to the oncology department. She said,

So I got my first appointment with Dr [anon] and, you know, I went in feeling fine and I got to that door outside the department and then felt sick to my stomach. And I hadn't felt that at all, but it was just those doors.

Contrasting this experience with, for example, how doors are described in Martin et al.'s (2019) article is revealing. For participants in their study, the doors appear to have had a symbolic quality as the material feature through which patients walk through in order to enter treatment and receive a warm greeting in doing so. More than this, their material characteristics 
were important too ("I love the doors, the sliding, they're quiet, they're graceful. All of those little touches that make a difference about being here" p. 5). Such examples, bring to the fore the sensory body's relational capacities - that is, "its capacities to act and interact with other entities within a network" (Andrews et al., 2014) - in a way that makes a simple 'door' more affecting than it otherwise would be if it were part of a different assemblage.

While the affective states which relied on the visual field were most easily recalled by participants in our study - perhaps reflecting the historical privileging of visual perception (Lupton, 2019) - there were certainly important aspects of the material environment that related to patients' embodied sensory capacities for sound, smell, temperature and touch. For example, there was a general agreement that the "bleeps" of the drips and the "buzzing" of alarms was a central component in the experience of irritation. One participant described the noise as "horrible" and another associated it with a feeling of "dread." For a participant in the highgrade lymphoma focus group, the sound of "those bloody machines" had a lasting associative memory,

I'd forgotten just how much that got to upset me by the end of it... By the end of it, I found the whole place really irritating and upsetting. I didn't really realise how much it was affecting me until on the odd occasion my wife came and met me and I was on edge. And the noise was one of the big things, especially when they're busy and it's endless. Bing-bong, bing-bong, bing-bong, bing-bong.

In Andrews et al.'s (2014) materialist articulation of sound which describes how atomistic vibrations come to be biologically affective, it is the sounds that humans recognise as discrete 'notes' with mathematical relationships to each other (such as the two notes of the 'bing' and 'bong' of the medical equipment in the oncology department) that are "pleasant to the ear." Our data add a caveat to this point, highlighting that sounds which are ostensibly musical and pleasant, come to elicit unpleasant visceral responses through their repetition, ubiquity and association with hospital treatment. 
Beyond vision and sound, the multi-sensory modality of experiencing cancer treatment in a hospital environment was illuminated through the anxiety and nausea experienced by one of the breast cancer patients as her body intra-acted with materials with the capacity to be smelt by human senses. She noted that "there is an odour that surrounds the place" and described her heightened sensitivity to smell by saying that, "the last thing you want to be doing when you come in through this - especially when you're feeling nauseous - is to go into a place that smells." Furthermore, the temperature was described as being uncomfortable ("everything was far too hot in the hospital") making it difficult to find a state of calm and relaxation. This heat was not only attributed to the central heating system in the building, but also because of the materials that patients physically came into contact with. One patient said, "the seats make you very hot. That was one thing that we did [give feedback about] because they're plastic." Resonating with the way in which Bissell (2008) describes comfort and discomfort as being produced through the material assemblage comprising the body and the proximate environment, sitting on the plastic seats became more uncomfortable as they became "sticky" through being in contact with patients' skin, typically when wearing shorts or skirts. As such, comparable to Brown et al. (2019), these experiences suggest that the plastic of the seating can be a significant material component of the experience of treatment.

\subsection{Affective qualities of human-human assemblages in shared spaces of care}

In this section, we explore how cancer patients' experiences are shaped by the altogether more socio-material assemblages that take place within the shared spaces of the hospital environment. We refer to these as human-human assemblages due to the direct nature of the intra-actions between patients, staff and visitors within the network of care which have been enabled by the material environment as well as the potential hierarchical social positioning of particular human agents within the shared clinical space. For example, the spatial 
arrangement of the oncology department within the hospital made patients feel as though they were being segregated or "tucked away" from the general hospital population. A breast cancer patient said, “OK there's radiation going on, there's chemotherapy going on, I understand that. But also, we don't have to feel like we're separate from anybody else." The conversation continued as follows:

And we don't want to feel like we're tucked away. Whereas here we feel like we're tucked away because we go up this little ramp and you're like, you're away from everybody else because you've got cancer! And you're infectious!

We're the ones that nobody wants to talk to! [laughter]

You know, it does feel a bit like that doesn't it. Because you're in there and then there's this other door.

'That's where people go when they've got no hair'.

Here, the spatial organisation of the oncology department, together with physical elements such as the "little ramp" and the "other door" served to exaggerate the sense of social difference experienced by patients - something for which it seemed there was an awareness of through existing identifiable characteristics like hair loss.

In addition to a sense of feeling socially segregated because of the building design, patients spoke of stress and embarrassment in spaces within the hospital where they were themselves in public view or auditory range of other patients and visitors. A significant issue for several of the breast cancer patients in our study was the lack of a private space - away from the gaze of others - especially after receiving a diagnosis. One participant simply explained:

I remember going out and crying in the waiting room with my daughter. I was just hugging her. She was crying. She was crying and I was crying. And it was in front of everybody. We had nowhere to go that was a private space. 
While the waiting room has been understood as a place of resentment and hostility between staff and patients (Akerstrom, 1997) as well as a place that can shape naturally occurring support and social interaction (Cohn, 2000), our analysis illuminates the capacity of the waiting room assemblage to produce tensions between intense pre-reflexive feeling states and conscious awareness of the public gaze. Another participant described going through a similar experience and referred to it as the "walk of shame" given her astute awareness of the likelihood that others would be noticing, judging and thinking about what she had just experienced.

I walked through that part looking back to where I'd been pre- 'me', pre- 'cancer me' and was just thinking, you know... that point was so traumatic because, you know, you're walking the walk of shame. Everybody's looking. "Is she crying?" "Oh, she's just being given that diagnosis". We all do it! We all sit in that fucking waiting room looking at people, coming... sorry [pauses] coming out. [pauses, crying]. We all do it. We look at people and we judge them. "Has she got hair?" "Is she wearing a wig?"

In this particular hospital, it is not insignificant that the waiting room where patients sit prior to their appointment with the oncologist is the same waiting room where patients sit following their appointment. This situation was experienced as "strange" because "suddenly the same space becomes quite different" after receiving a diagnosis, yet "you may be sat next to someone else who was oblivious to what's just happened to you." In these examples, the patients powerfully experienced the affective capacities of the human-human assemblage in the shared space of the waiting room. The capacity of the assemblage to affect altered between time points as the patient moved to a state of having received a diagnosis (being consciously aware of the cancer tissue within her physical body) which brought to the fore a vivid association between the patient and illness, and a disassociation between the patient and health (including her prior 'healthy' body-self). 
Enhancing the privacy of clinical spaces was also discussed, perhaps predictably, in reference to using toilet facilities. Prostate cancer patients - whose treatment involves drinking more than usual amounts of fluid before receiving medication and also self-administering enemas - would have preferred greater privacy instead of waiting to use toilets while "stuck out at the edge of the corridor". Clearly, the awareness of being in a social context was import in these cases, perhaps due to the risk of losing dignity (Brownlie and Spandler, 2018). The significance of shared proximal spatiality was also talked about by patients in the high-grade lymphoma group who were in-patients on several occasions:

The other thing on [the] ward is that you have to do your motions in these cardboard things... I was having to go every hour and if I had to do that in the ward and leave it in a communal toilet and everybody [pause]... and it's the most awful thing isn't it, having to leave your wee and everything else for people to see and smell and things.

In this example, the desire for bodily privacy extends to include matter that has left the body but is still associated with the need for dignity in shared spaces and has a temporal component because of the length of time that cardboard bed pans are left for.

Relatedly, many of the human-human patient experiences in shared space described by our participants can be understood through the notion that actual events and actions must be carefully coordinated. That is, hospitals are designed to be used by teams of healthcare staff working formally in cooperation to care for multiple patients who, in turn, must coordinate their activities, although in a less regulated and formal manner. When this coordination is problematic, it can impact negatively on patients' experiences. Continuing with patients' concerns about using toilets, the sharing of facilities became a cause of anxiety for some. One patient struggled when he felt "so physically unwell that that walk to the toilet is a real effort" and finding out that the toilet facility is occupied was challenging because "you can't risk walking to the next one." In this way, it is the co-presence of other patients, each with their 
own treatment-related needs, that makes this moment in the cancer treatment process feel disconnected with the ideal sense of autonomy and privacy that is experienced in more wholly private space such as the home (Buse and Twigg, 2014). For prostate cancer patients, the concern about occupied toilet facilities was not because of feeling physically unwell, but because of the sudden and urgent need to use facilities after administering enemas which was a source of significant apprehension specific to the cancer treatment for their particular diagnosis. Connections can be made here with the notion that bodies in treatment become temporarily 'unbounded' in that matter - be it faeces, urine, blood or other bodily fluids normally bounded within the confines of the body uncontrollably leave the body leading to patient embarrassment and, in extreme cases, patient withdrawal in search of complete isolation (Lawton, 1998).

The sharing of spaces also involved emotional encounters from patients when they cooccupied particular areas with other patients and their families. One participant spoke about the difficulties of accidentally encroaching on other patients during family visits;

So if you wanted to go and just go be somewhere different away from your ward, you'd go in there but there'd be like a big family in there experiencing whatever they're experiencing and that's not [pause] you kind of feel like you're intruding or... not intruding... It just doesn't feel like it's a comfortable place to be.

An unavoidable consequence of sharing spaces with other patients in the ward was that patients are witness to the ill health and sometimes painful experiences of others.

The ward is really hard with other people that are also on there just because you hear everything they're going through, and that can really affect you, like... The first time I stayed on the ward, it happened to be that there was a person there that was not doing very well at all, sort of thing. And they were just all night and all day, like, moaning about the situation that they were in.

And then do you start to think about yourself, like 'are they further down the line than me?' 
Yeah, you kind of go, 'is that my future?' kind of thing. 'I don't want to be like that.'

There are similarities here with the way in which Brownlie and Spandler (2018, p. 259) describe shared spaces, in that they "channel people in routinised ways into particular situations and interactions, which then create in participants the potential to recognise (but also resist) each other's needs". Indeed, Andrews et al. (2014) describe how such experiences can be thought of as "the happening of the ebbs and swells of intensities passing between bodies," reminding us that affective states should be seen not only as occurring within the fixed boundaries of individual patients, but across, between and through different agents in the network of relations.

Encounters with other patients in shared spaces, however, did not necessarily contribute to negative experiences. In many cases, interactions with other patients were welcome because talking to others helped patients understand if their symptoms were normal. Simply put, "it was nice to be able to discuss how you were feeling compared to how they [other patients] were feeling". Engaging with other patients during therapy was also seen as a "nice distraction" which entailed a meaningful relatedness and connectedness (other patients receiving therapy were described as "fellow compatriots" by one patient). For another patient: "you got to know people who are having radiotherapy at the same time because it's a daily thing. So that was quite a fun place, I enjoyed that." Again, the significance of cancer treatment is an important context to note because such positive experiences may have to be set against the backdrop of being in existing circumstances whereby opportunities for "emotional retreat and everyday sociality" (Bell, 2018) are seldom available. Indeed, following Andrews et al. (2014, p. 218), these subtle forms of sociality, or cognitive communications, provide opportunities for patients to "experience themselves expansively as more than themselves, as part of a greater physical happening" further contributing to the patient experience. While this was not experienced by 
everyone in our study and people described differences in preference both between patients and over time, these positive experiences can be contrasted with the general agreement that "when you're sitting there having chemo for nine hours and you don't have anybody with you and you're sitting there all alone, it's not very nice."

\subsection{Affective qualities of treatment practices that require material elements}

The third way that the material hospital building shaped patients' experience in our analysis was as a component part of the treatment practices that take place during patients' journeys through treatment. Here we take practices to mean the everyday 'doings' or 'enactments' that take place in the process of care carried out by patients and clinical staff with a focus on how materials either serve to sustain and enable practices or interrupt and constrain practices. Across the four focus groups, there were important examples of practices being impacted throughout the pathways of care. For instance, when patients had to carry out the practical task of attending therapy appointments, patients spoke of "frustration" or found it "a bit upsetting" particularly when appointments were early in the morning and thus entering and navigating the hospital was challenging. A complex architectural layout and locked doors proved to interrupt patients' attempts to carry out their practical tasks as a compliant patient, particularly because of the temporal sequencing of the treatment and patients' awareness of such temporality. The concerns of one patient appeared to revolve around being told to "always allow an hour for the prep" which made him anxious about being late and disrupting the planned set of events that would follow. This set of events was part of a "rhythm," or a "conveyor belt" for which patients "just want to get it over and done with, with minimum hiccups". In this way, the material environment of the hospital setting can potentially serve to help or hinder the practical actions that patients carry out during treatment, with affective consequences for the patient. 
Waiting room spaces also played an important part in the sequential treatment process. In the performance of being a 'good patient', patient experiences suggested that there was an inherent prioritizing of clinical practices over patient practices; indeed, the patients' movements are spatially contained so that they can be conveniently called into the workflow of the medical staff at a time when the medical staff are ready to accommodate them. Hence, the physical space of the waiting room enables the complex nexus of practices which make up the workflow of the medical staff to function efficiently. However, from the patient perspective, being spatially confined to the waiting room prevents patients from accessing their preferred places within the hospital site. Participants talked of being "stuck there" for fear of missing their name being called and therefore being unable to "go outside to the courtyard" for its "scenery" and "fresh air".

Receiving a diagnosis can also be seen as a practice enacted by patients which may involve a set of competences (such as listening and asking questions) and meanings (such as an understanding of the seriousness of the illness). For oncologists, the practice of delivering a diagnosis requires different competences and a different set of meanings. However, both delivering and receiving a cancer diagnosis effectively are contingent on the materials used in the interaction such as chairs, desks, doors and the walls of an office. One of the patients in our study spoke about how the physical environment shaped her experience of receiving a diagnosis for breast cancer as follows:

The [doctor's] room is absolutely tiny. There's not really anywhere to sit.

And you have to actually sit on the bed.

I sat on the bed, yeah.

If you've got a visitor. Your visitor sits on the chair and then the doctor stands and talks to you. The image you get of being told you've got cancer is, you know, sitting in front of the desk, you know, the doctor sitting in a chair. He's got reference books, you know. Whereas, you sort of feel like you're sat in this little poky room because you're not important enough. And you just feel that you... it's just really awkward to be told you've got cancer sitting on a bed, tiny little 
room with two doctors standing there - because mine was two doctors standing - talking to you. So for them to now tell me I am terminal, standing there in this tiny little room, no window at all... I wasn't sitting comfortably, as I was sitting on the bed. They need to make you feel that they are talking to you and you alone, they're not standing waiting to go out the door to talk to someone else.

In this example, it is interesting that the inadequacy of the material elements of the encounter was shaped by wider (and somewhat predictable) cultural expectations of what it is like to receive a cancer diagnosis.

Materials also played a part in sustaining or interrupting practices involved with the process of receiving treatment. This ranged from the practice of consuming cups of water in the waiting room prior to treatment which was made difficult by having no available table or cup holder ("that's a simple little thing but I found it quite frustrating"), to the challenges of having inadequate space when staff are delivering care. The challenges for staff were observed by patients and visitors which they found disruptive:

I found it disturbing, well not disturbing but... I mean sometimes after radiotherapy you've got someone coming through on a bed and quite often they'd have to manoeuvre through - cos there's so many people. Quite often there is someone in a wheelchair as well, yeah manoeuvring through.

This awkwardness was similar for visitors who were conscious of not wanting to get in the way of clinical staff when they were trying to perform treatment practices:

You tend to see them jump up and down every time the nurse comes by because they think they're in the way of the person next to you needing their treatment.

The role of the material environment in understanding how agents are recruited and encouraged to perform practices has been studied in relation to treatment practices in healthcare settings (Maller, 2015). In the context of cancer treatment, it is perhaps too extreme to suggest that material inadequacies would lead to patients disengaging with cancer treatment in the same 
way, but is possible that material inadequacies may interrupt and constrain the practices that a patient wishes to perform in trying to deal with treatment in a way which is best for their wellbeing. Indeed, at the very least, such interruptions may have minor, but not insignificant, implications for the patient experience, particularly if they are regular.

\section{Conclusions and implications}

In the context of the growing realisation that 'place matters' to health and wellbeing (Andrews 2014) as well as calls to pay more theoretical and empirical attention to materiality (Martin et al., 2015) a significant literature base has emerged that explores how material hospital environments contribute to patients' experiences. As Buse et al. (2018, p. 253) note, this is imperative because materialities "are increasingly in dialogue with healthcare practices, spaces and discourses of health, and thus deserving of our attention as medical sociologists interested in questions of care." The findings presented above align with and contribute to this scholarship but also offer several extensions to our understanding. The first of these is that our interest converges explicitly on the experience of the hospital environment while being treated for cancer - and, specifically, different types of cancer. As such, this study sheds light on how affect differentially manifests for patients going through different treatments and at different points in the patient journey. Similar to other studies (e.g. Ivanova et al., 2016; Greenhalgh and Stones, 2010), these particularities further illuminate how patient experiences are, at times, highly contingent on individual patients' complex and changing position with a wider nexus of human and nonhuman actors.

Although our aim was not explicitly to make conceptual contributions to materialist approaches in social science and medicine or affect theory, we are optimistic about the potential for our typology to be analytically useful for future research. The three ways in which the 
material hospital environment was affective (through patients' direct intra-actions with nonhuman materiality; through providing shared spaces within which human-human assemblages are actualised; and through being the material component of the practices of treatment) has value, in our view, in that they provided us with a plausible explanatory account that meaningfully and usefully connected our reflexive engagement with empirical data and abstract conceptualisations. These analytical distinctions may offer something new as heuristic - that is, imperfect but 'good-enough' - tools (Nisbett, 2019) to help us think through sometimes overwhelmingly complex issues.

While our findings do in many ways compliment other recent studies (see in particular Martin et al., 2019; Wright, 2019; Melo, 2018; Nettleton et al., 2018; Bell, 2018), we hope to have offered novel empirical insights which could have significant practical implications for those with an interest in optimising cancer patients' experiences. Such insights may be particularly valued for architects, designers and, indeed, healthcare professionals who may not otherwise have a meaningful 'way in' to patients' narratives (Buse et al., 2017). Data have, for example, revealed patient accounts of welcome, positive feeling states including feeling relaxed, calm and restful through sensory engagements with 'nature' including artistic and artificial representations of it - a finding that we find particularly interesting for health geographers interested in therapeutic landscapes. Such affective qualities between patients and the nonhuman environment are seen to have emerged as a property of various elements acting in relation to each other spatially and temporally within the hospital setting. Furthermore, welcome moments of affect through human-human assemblages in shared spaces of care included feeling positively distracted when interacting with other patients or feeling reassured when discussing symptoms with other patients.

Acknowledging the notion that it would be remiss to exclude negative feeling states from our burgeoning materialist understanding of health (Andrews and Duff, 2019), our study 
also empirically locates the precise points of concern where affect was problematic and unwelcome for patients. In the domain of patients' direct intra-actions with nonhuman materiality, data highlight, for example, experiences of feeling depressed when seeing low ceilings and dark rooms around the hospital, feeling daunted at the sight of the doors to the oncology department, and feeling irritated when hearing bleeps and buzzing of machinery during treatment. On the significance of shared spaces, we have shown that feelings of stress and embarrassment manifest when patients were in public view or in auditory range of other patients and visitors, and that feeling daunted was common when witnessing the ill-health experiences of other patients. Furthermore, in the domain of materiality as a component of the practices of treatment, we have noted how patients can feel spatially confined to the waiting room when clinical routines preclude them from accessing their preferred places within the hospital site and feeling awkward because the doctor's room was not conducive to patient expectations of receiving a diagnosis.

The implications of these findings may be that the materialities and practices of care should be - or, rather, should continue to be in many cases - recognised as inescapably holding causal potential in the production of experience. Hence, strategies to reproduce positive, welcome feeling states and to reduce unwelcome, negative feeling states might fruitfully use these empirical findings to ask how the elements of an assemblage can be differently spatially, temporally and socially organized. As such, further exploration into the intra-actions that might take place in various spaces within the hospital is justified in order to anticipate whether these are likely to be welcome or unwelcome at each stage of the patient journey while being treated for cancer. Although exercising epistemic humility is appropriate during these concluding remarks by avoiding the temptation to offer tangible recommendations for what these strategies might look like, we do at least support Elf et al.'s (2015) view that a range of stakeholders 
should be involved in shared decision making about the design of material hospital environments given the multi-layered complexities that this study, and others, highlight.

\section{References}

Andrade, C., Lima, M. L., Fornara, F. \& Bonaiuto, M. (2012). Users' views of hospital environmental quality: Validation of the perceived hospital environment quality indicators (PHEQIs). Journal of environmental psychology, 32(2), 97-111.

Andrews, G. J., \& Duff, C. (2019). Matter beginning to matter: On posthumanist understandings of the vital emergence of health. Social Science and Medicine, 226(February), 123-134. http://doi.org/10.1016/j.socscimed.2019.02.045

Andrews, G. J., Chen, S. \& Myers, S. (2014). The "taking place" of health and wellbeing: Towards non-representational theory. Social Science and Medicine, 108, 210-222. http://doi.org/10.1016/j.socscimed.2014.02.037

Arneill, A. B. \& Devlin, A. S. (2002). Perceived quality of care: The influence of the waiting room environment. Journal of Environmental Psychology, 22(4), 345-360. http://doi.org/10.1006/jevp.2002.0274

Barad, K. (2007). Meeting the Universe Halfway. London, UK: Duke University Press.

Barad, K. (2003). Posthumanist performativity: toward an understanding of how matter comes to matter. Signs, 28(3), 801-831.

Bell, S. E. (2018). Placing care: embodying architecture in hospital clinics for immigrant and refugee patients. Sociology of Health and Illness, 40(2), 314-326. http://doi.org/10.1111/1467$\underline{9566.12604}$

Bettencourt, B., Schlegel, R. J., Talley, A. E. \& Molix, L. A. (2007). The breast cancer experience of rural women: a literature review. Psycho-Oncology: Journal of the Psychological, Social and Behavioral Dimensions of Cancer, 16(10), 875-887.

Brownlie, J. \& Spandler, H. (2018). Materialities of mundane care and the art of holding one's own. Sociology of Health and Illness, 40(2), 256-269. http://doi.org/10.1111/1467-9566.12574

Buse, C., Martin, D. \& Nettleton, S. (2018). Conceptualizing 'materialities of care': making visible mundane material culture in health and social care contexts. Sociology of Health and Illness, 40(2), 243-255. http://doi.org/10.1111/1467-9566.12663

Buse, C., Nettleton, S., Martin, D., Twigg, J. (2017). Imagined bodies: Architects and their constructions of later life. Ageing and Society, 37(7), 1435-1457.

Butterfield, A. \& Martin, D. (2016). Affective sanctuaries: understanding Maggie's as therapeutic landscapes. Landscape Research, 41(6), 695-706. http://doi.org/10.1080/01426397.2016.1197386

Cancer Research UK (2019). General Cancer Information, Available online at https://www.cancerresearchuk.org/about-cancer [accessed 12/12/2019]

Coleman, T. \& Kearns, R. (2015). The role of bluespaces in experiencing place, aging and wellbeing: Insights from Waiheke Island, New Zealand. Health \& Place, 35, 206-217.

Coole, D. \& Frost, S. (2010). Introducing the new materialisms. In Coole, D., Frost, S. (Eds.), New Materialisms. Ontology, Agency, and Politics. Duke University Press, Durham, N.C. 
Cunningham, M. \& Wells, M. (2017). Qualitative analysis of 6961 free-text comments from the first National Cancer Patient Experience Survey in Scotland. BMJ open, 7(6), e015726.

De Vries, S., Verheij, R., Groenewagen, P., Spreeuwenberg, P. (2003). Natural environments healthy environments? An exploratory analysis of the relationship between greenspace and health. Environment and Planning, 35(10), 1717-1731.

Deleuze, G. \& Guattari, F. (1987). A Thousand Plateaus: Capitalism and Schizophrenia. Minneapolis: University of Minnessota Press.

Department of Health. (2008a) High Quality care for all: NHS Next Stage Review Final Report. London: The Stationery Office, Available online at: www.gov.uk/government/uploads/system/uploads/attachment_data/file/ 228836/7432.pdf [accessed 12/12/2019]

Department of Health. (2008b). A Staff and Patient Calibration Toolkit documentation, Available online at:

https://webarchive.nationalarchives.gov.uk/20130124042001/http://www.dh.gov.uk/prod_con sum dh/groups/dh_digitalassets/@dh/@en/documents/digitalasset/dh_082081.pdf [accessed $12 / 12 / 2019]$

Devlin, A. S. \& Arneill, A. B. (2003). Health care environments and patient outcomes: A review of the literature. Environment and Behavior, 35(5), 665-694. http://doi.org/10.1177/0013916503255102

Donetto, S., Penfold, C., Anderson, J., Robert, G. \& Maben, J. (2017). Nursing work and sensory experiences of hospital design: A before and after qualitative study following a move to allsingle room inpatient accommodation. Health and Place, 46(February), 121-129. http://doi.org/10.1016/j.healthplace.2017.05.001

Doyle, C., Lennox, L. \& Bell, D. (2013). A systematic review of evidence on the links between patient experience and clinical safety and effectiveness. BMJ Open; 3:e001570.

Elf, M., Frö, P., Lindahl, G. \& Wijk, H. (2015). Shared decision making in designing new healthcare environments-time to begin improving quality. BMC Health Services Research, 15(1), 1-7. http://doi.org/10.1186/s12913-015-0782-7.

Foglino, S., Bravi, F., Carretta, E., Fantini, M. P., Dobrow, M. J. \& Brown, A. D. (2016). The relationship between integrated care and cancer patient experience: A scoping review of the evidence. Health Policy, 120(1), 55-63.

Foley, R. (2015). Swimming in Ireland: Immersions in therapeutic blue space. Health \& Place. 35, 218-225.

Fox, N. J. \& Alldred, P. (2016). Sociology, environment and health: a materialist approach. Public Health, 141, 287-293. http://doi.org/10.1016/j.puhe.2016.09.015

Fullagar, S. (2017). Post-qualitative inquiry and the new materialist turn: Implications for sport, health and physical culture research,. Qualitative Research in Sport, Exercise and Health, 9(2), 1-24. http://doi.org/10.1080/2159676X.2016.1273896

Gardner, J. \& Cribb, A. (2016). The dispositions of things: the non-human dimension of power and ethics in patient-centred medicine. Sociology of Health and Illness, 38(7), 1043-1057. http://doi.org/10.1111/1467-9566.12431

Gesler, W., Bell, M., Curtis, S., Hubbard, P., \& Francis, S. (2004). Therapy by design: Evaluating the UK hospital building program. Health and Place, 10(2), 117-128. http://doi.org/10.1016/S1353-8292(03)00052-2

Global Cancer Observatory. (2019) Global Cancer Observatory, World Health Organisation. Available online at: https://gco.iarc.fr/[accessed 12/12/2019] 
Greenhalgh, T. \& Stones, R. (2010). Theorising big IT programmes in healthcare: Strong structuration theory meets actor-network theory. Social Science and Medicine, 70(9), 1285-1294. http://doi.org/10.1016/j.socscimed.2009.12.034

Huisman, E. R. C. M., Morales, E., van Hoof, J. \& Kort, H. S. M. (2012). Healing environment: A review of the impact of physical environmental factors on users. Building and Environment, 58(2012), 70-80. http://doi.org/10.1016/j.buildenv.2012.06.016

Ivanova, D., Wallenburg, I. \& Bal, R. (2016). Care in place: A case study of assembling a carescape. Sociology of Health and Illness, 38(8), 1336-1349. http://doi.org/10.1111/1467-9566.12477

Latour, B. (1996). On Actor-Network Theory: A Few Clarifications. Soziale Welt, pp.369-381

Latour, B. (2005). Reassembling the social: an introduction to actor-network theory. Oxford: Oxford University Press.

Lindberg, K., Walter, L. \& Raviola, E. (2017). Performing boundary work: The emergence of a new practice in a hybrid operating room. Social Science and Medicine, 182, 81-88. https://doi.org/10.1016/j.socscimed.2017.04.021

Llewellyn, H., Higgs, P., Sampson, E. L., Jones, L. \& Thorne, L. (2018). Topographies of 'care pathways' and 'healthscapes': reconsidering the multiple journeys of people with a brain tumour. Sociology of Health and Illness, 40(3), 410-425. http://doi.org/10.1111/1467$\underline{9566.12630}$

Lorimer, H. (2005). Cultural geography: the busyness of being 'more-than-representational'. Progress in Human Geography, 29(1), 83e94.

Lupton, D. (2019). The thing-power of the human-app health assemblage: thinking with vital materialism. Social Theory and Health, 17(2), 125-139. http://doi.org/10.1057/s41285-019$\underline{00096-y}$

Maas, J., Verheij, R., Groenewegen, P., De Vries, S. \& Spreeuwenberg, P. (2006). Green space, urbanity, and health: how strong is the relation? Journal of Epidemiology and Community Health 60, 587-592.

Maller, C. J. (2015). Understanding health through social practices: Performance and materiality in everyday life. Sociology of Health and Illness, 37(1), 52-66. https://doi.org/10.1111/14679566.12178

Martin, D., Nettleton, S. \& Buse, C. (2019). Affecting care: Maggie's Centres and the orchestration of architectural atmospheres. Social Science \& Medicine, 240(March), 112563. http://doi.org/10.1016/j.socscimed.2019.112563

Martin, D., Nettleton, S., Buse, C., Prior, L. \& Twigg, J. (2015). Architecture and health care: A place for sociology. Sociology of Health and Illness, 37(7), 1007-1022. http://doi.org/10.1111/1467-9566.12284

Maxwell, J. A. (2012). A realist approach for qualitative research. London: Sage.

McDougall, A., Goldszmidt, M., Kinsella, E. A., Smith, S. \& Lingard, L. (2016). Collaboration and entanglement: An actor-network theory analysis of team-based intraprofessional care for patients with advanced heart failure. Social Science and Medicine, 164, 108-117. http://doi.org/10.1016/j.socscimed.2016.07.010

Melo, S. (2018). The role of place on healthcare quality improvement: A qualitative case study of a teaching hospital. Social Science and Medicine, 202(October 2017), 136-142. http://doi.org/10.1016/j.socscimed.2018.03.003

Nettleton, S., Buse, C. \& Martin, D. (2018). 'Essentially it's just a lot of bedrooms': architectural design, prescribed personalisation and the construction of care homes for later life. Sociology of Health and Illness, 40(7), 1156-1171. http://doi.org/10.1111/1467-9566.12747 
Ronkainen, N. J. \& Wiltshire, G. (2019). Rethinking validity in qualitative sport and exercise psychology research: a realist perspective. International Journal of Sport and Exercise Psychology, 0(0), 1-16. https://doi.org/10.1080/1612197X.2019.1637363

Sayer, A. (2000). Realism and social science. London: Sage.

Schreuder, E., Lebesque, L. \& Bottenheft, C. (2016). Healing Environments: What Design Factors Really Matter According to Patients? An Exploratory Analysis. HERD: Health Environments Research \& Design Journal, 10(1), 1-19. http://doi.org/10.1177/1937586716643951

Selami Cifter, A. \& Cifter, M. (2017). A Review on Future Directions in Hospital Spatial Designs with a Focus on Patient Experience. The Design Journal, 20(sup1), S1998-S2009. http://doi.org/10.1080/14606925.2017.1352719

Shove, E., Pantzar, M. \& Watson, M. (2012) The Dynamics of Social Practices. Everyday Life and How it Changes. London, UK: Sage.

Thrift, N. (2008). Non-representational theory: space, politics, affect. London: Routledge.

Timmons, S., Vezyridis, P. \& Sahota, O. (2019). Trialling technologies to reduce hospital in-patient falls: an agential realist analysis. Sociology of Health \& Illness, $0(0), 1467-9566.12889$. http://doi.org/10.1111/1467-9566.12889

Ulrich, R. (1991). Effects of interior design on wellness: theory and recent scientific research. Journal of Health Care Interior Design, 3, pp. 97-109.

Ulrich, R. (1984). View through a window may influence recovery from surgery. Science, 224(4647), 420-421. http://doi.org/10.1126/science.6143402

Williams, A. (1998). Therapeutic landscapes in holistic medicine. Social Science \& Medicine 46(9), 1193-1203.

Wright, S. (2019). From 'holding pen' to 'a space to breathe': affective landscapes in a newlyintegrated sexual health clinic. Sociology of Health and Illness, $x x(\mathrm{xx}), 1-15$. http://doi.org/10.1111/1467-9566.12852 